\title{
INDICADORES DE SUSTENTABILIDADE APLICADOS AO DESIGN DE INTERIORES: ANÁLISE DO MODELO IDSRS
}

\author{
Ana Carolina de Lima Sarmento \\ Universidade Federal da Bahia/ Escola de Belas Artes \\ carol_sarmento@hotmail.com \\ Paulo Fernando de Almeida Souza \\ Universidade Federal da Bahia/ Escola de Belas Artes \\ paulosouza@ufba.br
}

Resumo: Os interiores revelam não só um espaço físico, mas também um ambiente psicológico de valores, gestos e significados. Com o objetivo de diminuir os impactos ambientais gerados por esses ambientes e consequentemente contribuir com o desenvolvimento sustentável, este artigo analisa uma metodologia de projeto que permita uma antecipação desses impactos, assim como a melhor adequação desses ambientes aos parâmetros de sustentabilidade. Apresenta como objeto de estudo e principal contribuição, uma possível adaptação do modelo IDSRS (Indicadores de Design, Sustentabilidade e Responsabilidade Social) para uso em design de interiores, desde a fase de concepção do projeto até o descarte, reciclagem e reuso do ambiente construído.

Palavras-chave: Design de Interiores, Indicadores de Sustentabilidade, Impactos Ambientais.

\begin{abstract}
The interiors reveal not only a physical space, but also a psychological environment values, gestures and meanings. In order to reduce the environmental impacts generated by these environments and thus contribute to sustainable development, this article analyzes a project methodology that allows an anticipation of these impacts, as well as the best fit of these environments to the parameters of sustainability. Presented as an object of study and main contribution, the adaptation of IDSRS model (Design Indicators, Sustainability and Social Responsibility) for use by interior design, from the very begining design stage to recycling, reuse and redesign of the built environment.
\end{abstract}

Keywords: Interior Design, Sustainability Indicators, Environmental Impacts. 


\section{INTRODUÇÃO}

Atualmente a indústria da construção civil é um dos principais setores da economia brasileira. Além de influenciar diretamente na economia, tem influência também no ambiente e na sociedade como um todo. É um setor que proporcionalmente ao seu crescimento, tem gerado impactos significativos ao meio ambiente, decorrente do mau gerenciamento de processos construtivos, utilização inadequada de recursos naturais e fontes não renováveis, retrabalhos e deposição de resíduos sólidos (ALVES e DREUX, 2015).

Profissionais de engenharia, arquitetos, designers de interiores, dentre outros inseridos no universo da construção civil, precisam estar conscientes de que um projeto pensado em conjunto será mais adequado do ponto de vista da sustentabilidade, aqui entendida como uma abordagem voltada para a redução dos impactos ambientais, permitindo o progresso econômico sem comprometer as futuras gerações (LEMOS e BARROS, 2007). Percebemos que os problemas ambientais são cada vez mais globais e não apenas restritos a territórios limitados, por isso, o conceito vem sendo discutido há décadas e têm evoluído de maneira a atender as necessidades do presente, conscientes das necessidades futuras.

Assim como Papanek (1995), Werner Sobek (Arquitetura e Construção, 2010) acredita na multidisciplinaridade como fator primordial na redução de impactos ambientais, ao comentar que:

A verdadeira sustentabilidade só pode ser alcançada se reunirmos clientes, arquitetos e engenheiros em estágios muito iniciais. No planejamento moderno e em processos de construção, as consequências ecológicas e econômicas que surgem de certas decisões são muito complexas para serem compreendidas por uma pessoa apenas. Só um processo de planejamento integral permite atingir uma solução excelente. (Arquitetura e Construção, 2010, p. 33)

Dentro dessa perspectiva, a alta taxa de mudanças em projetos de interiores, por exemplo, com ambientes sendo necessariamente renovados, e consequentemente gerando uma quantidade expressiva de resíduos ao meio ambiente, poderia ser evitada se houvesse maior interação entre os profissionais responsáveis pela cadeia produtiva, desde o planejamento até a implementação do projeto.

O design de interiores é definido por Brooker e Stone (2014, p. 11) como sendo "qualquer tipo de projeto de interiores, desde decoração até reforma. É a arte de decorar espaços interiores - cômodos ou ambientes - para transmitir uma identidade característica que funciona bem com a arquitetura existente". Com isso, podemos entendê-lo como uma possibilidade de transformar a geometria de um espaço, em um ambiente rico em emoções, sentidos e memórias que revelam a identidade de seus usuários. É o reflexo de um cotidiano que inclui manifestações socioculturais de uma comunidade, somadas a técnicas e materiais que se reciclam ao longo dos anos. No design de interiores, assume-se que cada detalhe tem sua importância ao longo da construção, desde a especificação de materiais, contratação de profissionais, até entrega dos móveis e utensílios projetados.

Ao falar sobre sustentabilidade no design de interiores nos deparamos com algumas limitações inerentes ao ambiente construído. Na maioria das vezes, 
associamos apenas a produtos ambientalmente responsáveis, uso de energia renovável e economia de água. Mas, o que falar dos empreendimentos certificados, que ao final da obra precisam ter seus interiores reformados para se adequar as necessidades individuais daqueles que o ocuparão? Não seria relevante refletirmos que o projeto de interiores é tão importante e norteador quanto projetos arquitetônicos, hidráulicos, e elétricos? Afinal, não existe planta elétrica ou hidráulica, que não considere um layout de ambientação como ponto de partida para seu desenvolvimento.

O artigo apresenta a primeira fase de um estudo desenvolvido no âmbito da pós-graduação em nível de mestrado. Este artigo objetiva a apresentação de uma possível antecipação de impactos ambientais no design de interiores, através de um modelo de indicadores de sustentabilidade, o modelo IDSRS (Indicadores de Design, Sustentabilidade e Responsabilidade Social), desenvolvido por Souza (2007) no contexto do design de produto, que neste estudo, é analisado de forma a contemplar seu uso também no campo do design de interiores. Inicialmente descreve-se o modelo e em seguida, por meio de uma análise exploratória, apresenta-se uma possível adaptação das suas fases, sobretudo sua forma de aplicação para uso em design de interiores.

\section{METODOLOGIA}

Este artigo é escrito a partir de uma pesquisa exploratória, com base na análise descritiva de um modelo originalmente desenvolvido no contexto do design de produto, com vistas a adaptá-lo para uso no campo do design de interiores. Gil (1994, p. 27) define que a pesquisa exploratória tem como principal finalidade, "desenvolver, esclarecer e modificar conceitos e ideias, tendo em vista a formulação de problemas mais precisos ou hipóteses pesquisáveis em estudos posteriores". Esse tipo de pesquisa nos permite, através de levantamentos bibliográficos, uma visão geral de assuntos pouco explorados. Neste caso, a sustentabilidade no design de interiores a partir de uma análise do seu processo de criação/execução.

A pesquisa exploratória nos permitiu aprofundamento com o tema e embasamento teórico. A partir disso, conforme descrito no tópico posterior, à análise descritiva do modelo IDSRS nos levou a interpretação de suas características para então sugerirmos sua possível adaptação ao campo do design de interiores.

\section{DESCRIÇÃO DO MODELO IDSRS}

Os indicadores de sustentabilidade, através de um modelo de avaliação, diagnóstico, comparação ou monitoramento, contribuem para o desenvolvimento de estratégias, e consequentemente, cooperam com a disseminação do desenvolvimento sustentável. É possível avaliar, por exemplo, o uso racional da água, da energia e atmosfera, a qualidade ambiental, materiais e recursos, conforto, gerenciamento, poluição, saúde e bem-estar. Independente da sua origem, critérios, diversidade e atuação, são salutares e benéficos para a sociedade e para o meio ambiente como um todo, uma vez que, passa a exigir de todos, uma nova visão de projeto (SOUZA, 2007).

O modelo IDSRS (SOUZA, 2007) busca o entendimento dos indicadores que possibilitem uma adequada tomada de decisões desde a fase de projeto, passando pela execução dos serviços de design, visando uma adequação quanto aos aspectos de sustentabilidade e redução de impactos socioambientais. A partir da análise descritiva 
do modelo, envolvendo uma revisão dos indicadores de sustentabilidade originalmente propostos, propõe-se uma possível adaptação ao design de interiores.

A figura 1 apresenta as quatro fases avaliadas no processo de design de produto através do modelo IDSRS, isto é: a) Produção; b) Manufatura; c) Reciclagem; d) Reuso/ Redesign (SOUZA, 2007).

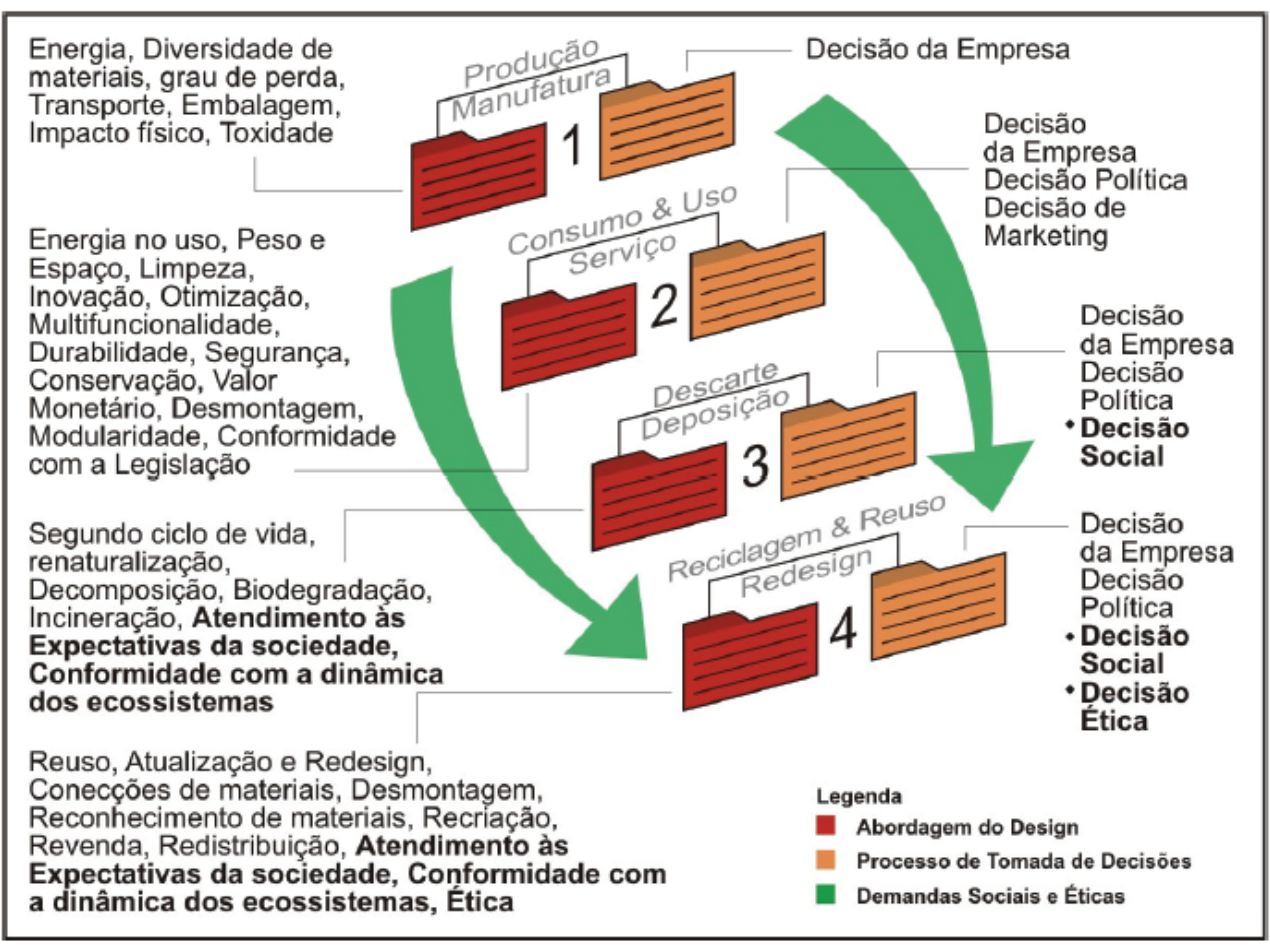

Figura 1 - Indicadores associados às demandas sociais e ambientais dos processos design. Fonte: SOUZA, 2007.

Observa-se que cada fase apresenta um conjunto de indicadores que auxiliam no processo de tomada de decisões. A primeira fase, Produção/Manufatura, avalia desde o consumo, a impactos físicos e toxidades do sistema produtivo. São decisões relacionadas à diretoria, de ordem interna da empresa. A fase 2 , Consumo, Uso e Serviço, avalia desde a capacidade de usos múltiplos de um mesmo produto a possibilidade de desmontagem. Diferente da primeira fase, as decisões dessa etapa partem do meio externo à empresa. As fases seguintes atuam no ciclo de vida do produto, sobretudo sua capacidade de decomposição, biodegradação e reutilização, que são decisivas no que diz respeito às expectativas da sociedade (SOUZA, 2007).

Para cada fase do modelo IDSRS foram atribuídos um número de indicadores, contudo, para cada indicador teremos uma quantidade de qualificações que podem ser ampliadas ou diminuídas de acordo com as necessidades específicas de cada sistema produtivo, conforme figura 2 . 


\begin{tabular}{|c|c|c|c|c|c|c|c|}
\hline Indicador & Descrição & $\begin{array}{l}\text { Concordo } \\
\text { Plena- } \\
\text { mente } \\
\end{array}$ & Concordo & $\begin{array}{l}\text { Concordo } \\
\text { em Parte }\end{array}$ & Discordo & $\begin{array}{c}\text { Discordo } \\
\text { Plena- } \\
\text { mente } \\
\end{array}$ & $\begin{array}{l}\text { Não se } \\
\text { Aplica }\end{array}$ \\
\hline \multirow{3}{*}{$\begin{array}{l}\text { Demanda } \\
\text { de energia } \\
\text { para } \\
\text { produção }\end{array}$} & $\begin{array}{l}\text { Não há grande demanda de energia para o } \\
\text { processo de produção em nossa empresa } \\
\text { (peso alto) }\end{array}$ & $\square$ & 凶 & $\square$ & $\square$ & $\square$ & $\square$ \\
\hline & $\begin{array}{l}\text { O uso de recursos naturais é planejado de } \\
\text { forma a otimizar o consumo energético do } \\
\text { sistema (peso alto) }\end{array}$ & $\square$ & 凶 & $\square$ & $\square$ & $\square$ & $\square$ \\
\hline & $\begin{array}{l}\text { A energia utilizada no processo produtivo é } \\
\text { gerada internamente (a empresa gera sua } \\
\text { própria energia para produção, } \\
\text { independente de fornecimento externo) } \\
\text { (peso médio) }\end{array}$ & $\square$ & $\square$ & $\square$ & $\square$ & $\otimes$ & $\square$ \\
\hline
\end{tabular}

Figura 2 - Aplicação da escala Likert ao modelo IDSRS.

Fonte - SOUZA, 2007.

As formulações para a qualificação dos indicadores são montadas com base na escala Likert, modelo de escala psicométrica, usada habitualmente em questionários e pesquisas de opinião, que registra o nível de concordância ou discordância de uma determinada declaração (PARO, 2012). Para cada resposta é atribuído um critério, que vai desde 0 (discordo plenamente ) a 4 (concordo plenamente), além disso observa-se um critério de validação neutra, para casos em que a qualificação não se aplica (SOUZA, 2007).

A fim de valorizar a importância de cada indicador, sobretudo o seu nível de responsabilidade socioambiental nas quatro fases estabelecidas, Souza (2007), atribuiu diferentes pesos a cada resposta. Segundo o autor, estes pesos são utilizados como fatores multiplicadores, possibilitando uma maior precisão na geração do dado quantitativo final. O modelo IDSRS prevê que alguns indicadores têm um grau de relevância maior que outros e por isso a estes, devem ser atribuídos pesos maiores. Após contabilizados os pesos de cada qualificação, quantifica-se o indicador de acordo com uma fórmula desenvolvida durante o estudo. Por fim, estes resultados são apresentados em uma escala de visualização conforme figura 3. Esta escala permite aos envolvidos no projeto, identificar pontos durante o processo de produção que necessitam de mais atenção, evidenciando a necessidade de correções em busca da diminuição de impactos ambientais.

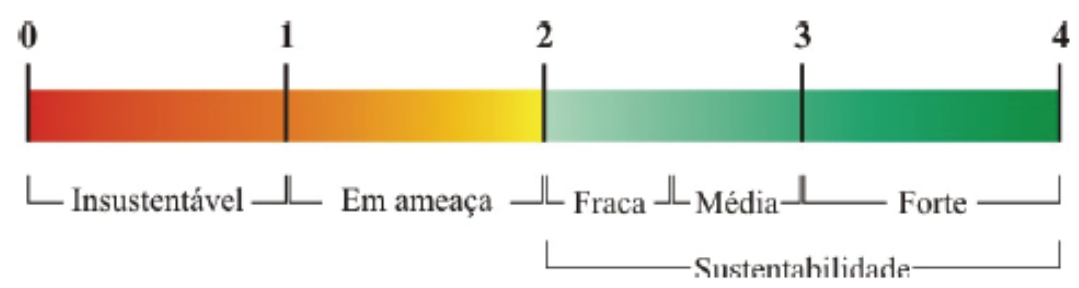

Figura 3 - Escala proposta para visualização dos resultados do modelo IDSRS. Fonte - SOUZA, 2007

Com base na análise descritiva de cada fase, com foco na gestão de projeto, materiais, energia, água e no sequenciamento adequado das etapas ao longo de todo processo, refletimos sobre sua possível adaptação ao design de interiores, compreendendo que desde a criação até a concretização do projeto, podemos aplicar indicadores objetivos e subjetivos de mesma relevância, que contribuem com a diminuição de impactos ambientais. 


\section{MODELO IDSRS APLICADO AO DESIGN DE INTERIORES}

Em um país onde se estima que mais de $50 \%$ dos resíduos sólidos gerados são provenientes da construção civil (CBIC, 2013), com problemas ambientais cada vez mais recorrentes, como, esgotamento de matriz energética, mudanças climáticas, escassez de recursos naturais e grandes volumes de resíduos, o uso de indicadores possibilita uma adequada tomada de decisão em todas as etapas da construção, adequando-a, aos parâmetros da sustentabilidade e consequentemente reduzindo os impactos socioambientais.

Papanek (1995, p. 115) destaca que,

a arquitetura só pode prosperar se as habitações construídas estiverem em harmonia com as pessoas que vivem nelas, com a natureza e com a cultura. Isso significará um passo grande para os utilizadores e para a sustentabilidade do ambiente construído.

Seguindo os ensinamentos de Papanek (1995), quando pensamos em ambientes concebidos de forma harmônica com as pessoas que neles conviverão, refletimos sustentabilidade e consequentemente contribuímos com 0 desenvolvimento sustentável. A Organização das Nações Unidas para Educação, Ciência e Cultura, UNESCO, define o desenvolvimento sustentável como, "a nossa capacidade de imaginar um mundo melhor e agirmos nessa direção. Sustentabilidade não é opcional. É o único caminho a seguir". De forma contrária ao que geralmente se ver, projetos sustentáveis podem e devem influenciar o desenvolvimento sustentável quando inseridos como uma prática de um projeto de qualidade e não como uma opção de escolha (EDWARDS, 2013; MOXON, 2012).

Com o pensamento voltado para projetos sustentáveis que vão além da especificação de um produto ecologicamente correto, utilizaremos o modelo de indicadores IDSRS adaptado, com o objetivo de antecipar os impactos ambientais, através de parâmetros de sustentabilidade que contribuam na transformação da prática do design de ambientes. A princípio redefinimos algumas fases e inserimos a fase de Pré-projeto, como fase I, por julgar que alguns detalhes são importantes e norteadores para concepção de um projeto sustentável.

Observamos que a fase I de Pré-projeto avalia o terreno/espaço antes mesmo da concepção do projeto, isto é, avaliamos a acessibilidade a serviços e transportes públicos, o conforto do entorno, assim como a preservação da vegetação existente (ver quadro 1). Julgamos que esses indicadores da fase I, devem ser levados em consideração por interferir diretamente na fase de projeto (fase II). Por exemplo, adotando como partida a avaliação do conforto do entorno, encontraremos o nível de ruído da região. A partir disso saberemos se esses ruídos estão dentro do nível permitido pelas agências fiscalizadoras e consequentemente o levaremos em consideração durante a fase de projeto ao definir o projeto de acústica, quando necessário.

A fase II, definida como a fase de Projeto, avaliará, por exemplo, a orientação solar, a acessibilidade, o conforto ambiental, e a economia de água e energia (ver quadro 1). É a fase mais importante por ser norteadora para as demais. Nesta fase destacamos a importância do designer de interiores para a definição do Layout do projeto, tomando como partida o projeto arquitetônico. Com isso é definido os demais projetos que precisam ser concluídos para início da obra. 
Quadro 1 - Modelo IDSRS adaptado para uso no design de interiores.

\begin{tabular}{|c|c|}
\hline Fase & Indicadores \\
\hline I. Pré- projeto & $\begin{array}{l}\text { - Terreno } \\
\text { - Transportes públicos e serviços acessíveis } \\
\text { - Preservação da vegetação existente } \\
\text { - Conforto ambiental }\end{array}$ \\
\hline II. Projeto & $\begin{array}{l}\text { - Conforto ambiental } \\
\text { - Flexibilidade da construção } \\
\text { - Acessibilidade/mobilidade } \\
\text { - Economia de água e energia } \\
\text { - Conformidade com a legislação }\end{array}$ \\
\hline III. Implementação/Execução & $\begin{array}{l}\text { - Gestão do projeto } \\
\text { - Comunicação entre os envolvidos } \\
\text { - Adequação dos materiais } \\
\text { - Grau de toxidade } \\
\text { - Economia de água e energia } \\
\text { - Conformidade com a legislação }\end{array}$ \\
\hline IV. Consumo/Uso/Serviço & $\begin{array}{l}\text { - Facilidade para manutenção } \\
\text { - Automação } \\
\text { - Bem-estar } \\
\text { - Economia de água e energia } \\
\text { - Multifuncionalidade } \\
\text { - Conformidade com a legislação } \\
\text { - Conforto ambiental }\end{array}$ \\
\hline V. Descarte/Reciclagem/Reuso & $\begin{array}{l}\text { - Gestão de resíduos } \\
\text { - Deposição/Descarte, } \\
\text { - Facilidade na desconstrução } \\
\text { - Conformidade com a legislação e } \\
\text { - Reciclagem }\end{array}$ \\
\hline
\end{tabular}

Fonte: Elaborado pelo autor, com base na pesquisa realizada.

A fase III, de Implementação/Execução avaliará a escolha dos materiais, a construção do canteiro de obra, a economia de água e energia durante a construção, a comunicação entre os envolvidos no projeto, assim como, o grau de toxidade e a conformidade com a legislação. A fase IV de Consumo, Uso e Serviço diz respeito ao ambiente já construído. Avalia a facilidade para manutenção, a economia de agua e consumo energético dos produtos especificados, assim como o uso da automação e o bem estar de seus usuários. Por fim, a última fase, Descarte/Reciclagem/Reuso, está relacionada aos resíduos da construção, ao descarte e reutilização do entulho, assim como, a facilidade de reconhecimento de materiais utilizados.

Observamos que todas as etapas da construção são interdependentes e uma complementa a eficácia da outra quando adequadas aos critérios da sustentabilidade. Destacamos que a fase II por se tratar, de fato, da concepção do projeto torna-se a mais relevante de todas e por isso, norteadora para as demais. É nessa fase que ressaltamos a importância da atuação do designer de interiores para definição do layout dos ambientes. Layout este que deve estar de acordo com as necessidades reais de seus usuários, e não executado de forma genérica para concepção dos demais projetos. Ressaltamos também que nesse modelo adaptado nem sempre todos os indicadores serão aplicados a todos os projetos, e nem todas as fases serão 
consideradas, visto que, alguns se encontrarão em estágios mais avançados de construção.

Neste momento, o projeto se encontra em fase de contextualização de todos os indicadores, assim como a atribuição de pesos ao mesmos, de acordo com seu grau de relevância e situação que virá a ser aplicado. Posteriormente pretende-se aplica-lo através de um estudo de caso. Por fim, acreditamos que os indicadores de sustentabilidade é uma prática que nos leva a tomar decisões baseadas em parâmetros de sustentabilidade. Sua utilização contribui com a antecipação dos impactos ambientais e com um ambiente técnico mais definido, estabelecendo claramente o papel de todos os agentes envolvidos.

\section{CONCLUSÃO}

Os interiores revelam não só um ambiente físico, mas também um ambiente psicológico de valores, ou seja, uma simbologia de gostos e significados. Os valores dizem respeito a nossa conscientização em relação ao ambiente natural. Se o ser humano precisa viver como um todo integrado e interdependente, é necessário que ele identifique qual o grau de equilíbrio entre a integridade desses ambientes construídos e sua exploração destrutiva. O uso de indicadores de sustentabilidade deve ser compreendido como uma ferramenta estratégica que propõe novas maneiras de projetar.

Ainda que seja desafiador, precisamos evoluir na relação entre sociedade e meio ambiente, para que tenhamos harmonia entre ambos. É preciso repensar maneiras de vivenciar o cotidiano interagindo com a natureza e gerando menos impactos ao meio ambiente. A multidisciplinaridade na busca de soluções entre os envolvidos na perspectiva da construção civil, por exemplo, é de suma importância quando pensamos na sustentabilidade. Arquitetos, engenheiros e designers são indispensáveis na sua função e precisam definir juntos projetos que desejam contribuir com o meio ambiente diminuindo os impactos ambientais na construção civil.

\section{REFERÊNCIAS}

ALVES, J. C.; DREUX, V. P. Resíduos da construção civil em obras novas. In.: Periódicos Interfaces Coletivas - Científicas e Exatas, V. 1, N. 1, p. 53-65. Disponível em: file://C:/Users/Ana\%20Carolina/Downloads/1812-6201-3-PB\%20(1).pdf. Acesso em: 22.11.2015.

ARQUITETURA E CONSTRUÇÃO. Edição especial Construção Sustentável. ed. 1. São Paulo: Abril, 2010.

BROOKER, G.; STONE, S. O que é design de interiores? São Paulo: Editora Senac São Paulo, 2014.

CBIC. Câmara Brasileira da Indústria da Construção (CBIC). Banco de Dados. Disponível em: http://www.cbicdados.com.br/home/ Acesso: 25.11.2015.

EDWARDS, B. O Guia Básico para a sustentabilidade. 1o ed. São Paulo: G. Gill, 2013.

GIL, A. C. Métodos e técnicas de pesquisa social. 6. ed. São Paulo: Atlas, 2008. 
LEMOS, Haroldo Mattos; BARROS, Ricardo Luiz Peixoto. 0 desenvolvimento sustentável na prática. Rio de Janeiro: Comitê Brasileiro das Nações Unidas para o Meio Ambiente, 2007.

MOXON, S. Sustentabilidade no design de Interiores. Amadora: Editorial Gustavo Gili, SL, 2012.

PAPANEK, Victor. Arquitectura e Design. Ecologia e ética. Lisboa: Edição 70, 1995.

PARO, B. A escala Likert - coisas que todo pesquisador deveria saber. Disponível em: http://www.netquest.com/blog/br/a-escala-likert-coisas-que-todo-pesquisadordeveria-saber/ Acesso: 29.11.2015.

SOUZA, P. F. de A. Sustentabilidade e Responsabilidade Social no design do produto: rumo à definição de indicadores. 2007. 294 f. Tese de Doutorado - Faculdade de Arquitetura e Urbanismo, Universidade de São Paulo, São Paulo, 2007. 